\title{
MURALLAS, DE GABRIEL BERNAL GRANADOS. UNA LECTURA A LA LUZ DE LA TRADICIÓN MEXICANA DE LA NOUVELLE SOBRE LA MEMORIA Y EL AUTODESCUBRIMIENTO
}

\author{
Juan Tomás Martínez Gutiérrez \\ Universidad de Guadalajara (México) \\ tomas_mtz@yahoo.com.mx
}

RESUMEN: En este artículo se propone que Murallas (2015) de Gabriel Bernal Granados puede ser leída como una novela corta o nouvelle. Así considerada se enmarcaría dentro de una tradición de las letras mexicanas caracterizada por llevar a la ficción la rememoración del tránsito de la infancia a la vida adulta, las primeras exploraciones de la sexualidad y el autodescubrimiento de los protagonistas. Esta tradición incluye obras como Elsinore: un cuaderno, de Salvador Elizondo, Las batallas en el desierto, de José Emilio Pacheco y Unión, de Juan García Ponce, por ejemplo. Asimismo, esta aproximación explora algunos elementos que constituyen la poética de Murallas; se analizan principalmente tópicos como unidad, dispersión y fisura.

PALABRAS CLAVE: nouvelle, poética, género literario, memoria, autodescubrimiento

\begin{abstract}
This essay will focus on the possibility to read Murallas (2015) written by Mexican author Gabriel Bernal Granados, as a novella, specifically, as a novella about memory and self-discovery. In Mexico this tradition would include works such as Elsinore: un cuaderno by Salvador Elizondo, Las batallas en el desierto by José Emilio Pacheco and Unión by Juan García Ponce, for example. In addition, the article seeks to explore some elements that constitute the poetics of Murallas; topics such as unity, dispersion and fissure are mainly explored.
\end{abstract}

KEYWORDS: novella, poetics, literary genre, memory, self-discovery

Se acabó esa ciudad. Terminó aquel país. JosÉ EMILIO PACHECO. Las batallas en el desierto.

Gabriel Bernal Granados (México, 1973) es autor de libros de poesía (Simulaciones, 2000; Sobre una hoja, 2010), aforismos (Partituras 2000; Detritos, 2015), ensayo (En medio de dos eternidades. Ensayos sobre literatura, 2007; Anotaciones para una teoría del fracaso, 2016) y Juan Tomás Martínez Gutiérrez: "Murallas, de Gabriel Bernal Granados. Una lectura a la luz de la tradición mexicana de la nouvelle sobre la memoria y el autodescubrimiento" 
narrativa corta (Murallas, 2015); es traductor y codirector de la editorial independiente Libros Magenta. Murallas, el volumen que ahora nos ocupa, es un libro difícil de clasificar: en diferentes notas periodísticas y reseñas es descrito como un conjunto de cuentos, colección de relatos o novela, o bien como un híbrido genérico. ${ }^{1}$ El hecho de que el título haya aparecido en la colección El Guardagujas, ${ }^{2}$ referente del cuento y del relato breve contemporáneo, más que zanjar la discusión, despliega una serie de cuestiones sobre las maneras en que la obra puede ser abordada.

En este artículo propongo que Murallas puede ser leída como una novela corta o nouvelle. Así considerada se enmarcaría dentro de una tradición de las letras mexicanas caracterizada por llevar a la ficción la rememoración del tránsito de la infancia a la vida adulta, las primeras exploraciones de la sexualidad y el autodescubrimiento de los protagonistas. La lectura de esta obra como nouvelle no descansa en un afán taxonómico; propongo que un análisis sobre su conformación genérica permite apreciar cómo varias problemáticas textuales se insertan en un ambicioso proyecto estético y de qué manera surgen nuevas posibilidades de interpretación de aspectos en apariencia secundarios: las oscilaciones de la voz narrativa, los matices y alteraciones en la estilización realista, el papel de la memoria y su configuración, entre otros. Como veremos, Murallas, en cuanto novela corta, resulta una afortunada aportación a un género maleable y confirma la vitalidad y los nuevos derroteros de una temática de gran arraigo.

Murallas es una narración segmentada en la que predomina la primera persona. No fragmentaria, puesto que este último adjetivo connota una narración cercana al collage, superficie conformada por retazos dispersos unidos por patrones más o menos fortuitos. La obra, al contrario, se integra por seis apartados: "7:19", "Ventana al mar", "89", "P", "Arena Coliseo" y "90", que en su conjunto narran, aproximada pero no linealmente, cinco años en la vida de un personaje en su paso a la edad adulta, entre los 14 y los 19 años. En México corresponde al lapso entre la educación secundaria y los tres años de bachillerato (nivel preuniversitario). Asimismo, la estructura del texto ofrece, en clave, las coordenadas espaciotemporales en las que se desarrolla la historia: el inicio de la narración traslada al lector al año 1985, al Distrito Federal, ${ }^{3}$ y termina en el otoño de 1990. Un primer elemento que permite considerar la obra como una unidad dividida en segmentos es, por lo tanto, ese rasgo de progresión temporal que enmarca el crecimiento y desarrollo del protagonista. En Murallas, un narrador da cuenta de sus recuerdos de esos años: inicia con un accidente que fractura su cuerpo y un incidente que fractura su ciudad

\footnotetext{
${ }^{1}$ Véase: Aguilar, 2015; Secretaría de Cultura, 2015; Estrada, 2015; González, 2016.

2 Editada por la Dirección General de Publicaciones del Consejo Nacional para la Cultura y las Artes (CONACULTA). El título de la colección alude al cuento homónimo de Juan José Arreola, por lo que constituye un homenaje al autor nacido en Ciudad Guzmán, Jalisco, y a su incansable labor de difusión de la narrativa breve. Constancia de esta actividad es la colección hoy mítica en la historia de la literatura mexicana "Los presentes", en la que aparecieron por primera vez títulos como Lilus Kikus (1954), de Elena Poniatowska, Los días enmascarados (1954), de Carlos Fuentes o La tumba (1964), de José Agustín, entre otros.

${ }^{3}$ El título del primer apartado, "7:19", se refiere a la hora de inicio del peor terremoto de la historia moderna del país ocurrido el 19 de septiembre del año señalado.

Juan Tomás Martínez Gutiérrez: "Murallas, de Gabriel Bernal Granados. Una lectura a la luz de la tradición mexicana de la nouvelle sobre la memoria y el autodescubrimiento" 
natal y, con ella, su vida misma; se narra después el primer amor marcado por la inocencia, la amistad y la necesidad de formarse una identidad ante los demás y para sí mismo; aparece, más tarde, un amor tormentoso, un viaje con tintes chamánicos y el papel del arte (pintura, literatura, cine) en su formación y en la interpretación del mundo. Es, en suma, una narración sobre la necesidad de comprender el pasado, de narrarlo para desprenderse de él.

Este acercamiento es deudor de la reseña de Sergio González Rodríguez, titulada "Escribir libros como se escriben cartas a un amigo", en la que señala que esta obra "se lee como una novela de aprendizaje; pero esta novela de aprendizaje se sitúa en una tradición que en los últimos cuarenta años se ha dado en la literatura mexicana" (2016), y cita como ejemplos Las batallas en el desierto (1980), de José Emilio Pacheco, Muchacho en llamas (1987), de Gustavo Sainz, Elsinore: un cuaderno (1988), de Salvador Elizondo y Unión (1974), de Juan García Ponce. Me interesa tomar y reformular dos aspectos de su propuesta: por un lado, la idea de novela de aprendizaje, y por otro, la propuesta de una tradición viva dentro de las letras mexicanas.

Acerca de la primera cuestión, resulta un gran acierto de Sergio González no denominar Bildungsroman a este tipo de novela, ya que si bien puede retomar ciertos elementos de aquel género que alcanzó su forma clásica en lengua alemana, el horizonte cultural de los títulos que ahora nos ocupan hace imposible trasladar el término sin tergiversar el conflicto individuosociedad y la idea misma de formación $($ Bild $) .{ }^{4}$ "Novela de aprendizaje" podría resultar una denominación viable, puesto que desplaza el peso de las tradiciones filosóficas en las que surgió el género $\mathrm{y}$, atendiendo a dicho elemento temático, permite situarnos en coordenadas culturales concretas. Sin embargo, aunque se trata de personajes adolescentes, del crecimiento y autodescubrimiento como temas centrales, el término todavía podría desvirtuar las peculiaridades de estas propuestas literarias. Entonces, ¿qué elementos deberían ser considerados para ubicar mejor esta tradición dentro de un panorama tan amplio como el de la literatura escrita en México, cuyos protagonistas son adolescentes?

En los ejemplos ofrecidos por Sergio González es posible percibir otros aspectos compartidos: son narraciones en primera persona en las que la memoria no solo es un tema, sino el prisma articulador del relato y, de manera simultánea, el mecanismo conformador de la identidad narrativa. Murallas, de una forma similar a Elsinore y Las batallas en el desierto, enfatiza por diversos medios la distancia temporal de lo narrado respecto al tiempo de la escritura. Tal es el centro de este tipo de obras: una voz que narra en primera persona el tránsito

\footnotetext{
${ }^{4}$ Miguel Salmerón, en La novela de formación y peripecia, señala cinco rasgos que posee un Bildungsroman: 1) En la novela de formación la historia de formación del protagonista no es solo el tema, sino también el principio poético de la obra; 2) La novela de formación es una forma que se busca a sí misma y que intenta mantenerse equidistante entre la instrucción y la peripecia; 3) El final de las novelas de formación es, y solo puede ser, utópico o fragmentario; 4) La novela de formación no es exclusiva ni originariamente alemana, pero llega a su forma clásica en Alemania; 5) En la novela de formación aparecen de forma recurrente figuras como el protagonista, el mentor, el antagonista, la mujer, el viaje, una institución que todo lo dirige, etc. (2002: 59-60).

Juan Tomás Martínez Gutiérrez: "Murallas, de Gabriel Bernal Granados. Una lectura a la luz de la tradición mexicana de la nouvelle sobre la memoria y el autodescubrimiento" 
entre la infancia y la juventud desde un ahora que hace visibles y significativas las difusas fronteras entre el trabajo de rememoración y la ficción literaria. ${ }^{5}$ Es posible que esa sea la razón por la que entre sus ejemplos no cita obras como La tumba (1964), de José Agustín o a Gazapo (1965), de Gustavo Sainz, porque si bien son ficciones sobre la experiencia de crecimiento y descubrimiento, establecen una relación muy distinta entre el tiempo de la escritura y el tiempo representado (hay una cercanía que connota cierta inmediatez), así como entre la identidad del narrador y autor real (Gabriel Guía y Menelao, respectivamente).

Otro rasgo que comparten las obras enumeradas es la brevedad, y esa es la segunda cuestión que extraigo de la lectura de Sergio González: con la excepción de Muchacho en llamas, estamos ante nouvelles acerca de la memoria y el autodescubrimiento, caracterización que adopto para dar título a este trabajo. González no abunda en este atributo en apariencia evidente. Es probable que la omisión sea reveladora respecto al lugar, casi marginal, que ocupa en algunos segmentos de la crítica la reflexión sobre la forma y la historia del género nouvelle en América Latina. Nadie diría que Las batallas en el desierto es un cuento, pero la idea de que pertenece a un género aparte de la novela tampoco parece suficientemente extendida. Sin embargo, sostengo que si este tipo de obras han conformado ya una tradición, ha sido porque en la eficaz ejecución y apropiación de la forma narrativa se han logrado universos estéticos que se debaten entre la intensidad y la expansión propia del género (Leibowitz, 1974). Dicho de otro modo: la difusa frontera del género, de un "género incierto" (Piglia, 2006: 201), parece haberse conjugado armónicamente para representar el momento vital, fronterizo y contundente del paso a la vida adulta.

\section{Oscuridad y fisuras en el inicio}

Ricardo Piglia afirma que una nouvelle nunca descifra por completo los enigmas que plantea, y es así debido a una lógica narrativa: para desarrollar dichos enigmas tendría que desarrollar todas las tramas implícitas, entonces sería necesario escribir una novela y no un tipo de relato de la densidad, concentración y duración de la nouvelle (2006: 200). Retomo la reflexión de Piglia porque Murallas es, entre otras cosas, una serie de enigmas: desde el título y el epígrafe, hasta

\footnotetext{
${ }^{5}$ Aventuro una hipótesis acerca de por qué estos autores incursionaron en una forma y una temática similar. Se trata de obras escritas por autores que nacieron en la década de los treinta y principios de los cuarenta, vivieron de cerca la agitación de los años sesenta y, aunque ya no eran adolescentes, compartieron un horizonte discursivo en el que el papel de la juventud y la contracultura ocuparon un lugar central. Ese contexto pudo ser determinante para visibilizar de otra manera la propia experiencia y su representación literaria. Por otro lado, escribieron los títulos mencionados cuando estaban entre los cuarenta y los cincuenta y seis años de edad. La integración de esa diferencia a la literatura, de ese desfase entre lo narrado y la reflexión desde un presente, configura un objeto estético en que se mezclan la narración y la reflexión erudita sobre el mundo evocado. En estas problemáticas, que sin duda deben ser exploradas con mayor detenimiento, puede encontrarse una de las claves para comprender por qué la idea de sujeto, mundo y experiencia no pueden asimilarse a aquellos propios del Bildungsroman.

Juan Tomás Martínez Gutiérrez: "Murallas, de Gabriel Bernal Granados. Una lectura a la luz de la tradición mexicana de la nouvelle sobre la memoria y el autodescubrimiento" 
aquellos representados en la historia o los que surgen de la forma en la que la voz narrativa se posiciona respecto a lo narrado.

En algunas obras, el papel de los paratextos (Genette, 2001) cobra una relevancia capital, y es así el caso de Murallas. Anticipan una problemática, proporcionan una clave para descifrar un enigma; o bien, como veremos en las siguientes líneas, no necesariamente lo aclaran, sino que lo redimensionan, lo inscriben en una lógica particular tendiente a multiplicar y diversificar sus connotaciones. El epígrafe del volumen, a propósito, señala: "Los seres humanos no han podido resolver esto todavía. El genio sigue siendo para ellos no el inexpresivo, que surge de la noche, sino uno expresivo que vibra y se mantiene entre la luz. —Walter Benjamin, «Sócrates»". Al título del primer capítulo, “7:19”, le sigue un segundo epígrafe que es en realidad un fragmento ligeramente modificado del primero: "Vibra entre la luz...". Revisaré con mayor detenimiento el primer capítulo, partiendo de la hipótesis de que analizar algunas de sus problemáticas estructurales y temáticas, así como sus interrelaciones, resulta útil para comprender la poética de Murallas.

La imagen del genio que vibra y se mantiene entre la luz se relaciona, en el plano de la anécdota, con la secuencia inicial: el narrador y su amigo César avanzan a toda velocidad en bicicleta sobre una pista asfaltada - en el Autódromo Hermanos Rodríguez - a una hora del día en la que el sol, por una ilusión óptica, parece deformar el piso, dotándolo de la textura de una naranja. Las ruedas de los vehículos se tocan accidentalmente, los ciclistas caen y todo alrededor se apaga. El protagonista queda inconsciente por un momento. La narración inicia con la luz, pero lo que narra es el término de esa luz:

Ese fue el momento preciso de mi muerte. ¿Duró segundos o milenios? No lo sé con certeza. Lo único cierto es que duró ambas cosas, segundos y milenios, fundidos en una masa aceitosa que podía moldearse entre unas manos que no eran precisamente mías. Porque alguien moldeaba esa masa muy similar a la plastilina en la que se debatía la continuidad de una vida o su cancelación inapelable. (12)

La imposibilidad para definir con precisión los contornos de un hecho no deriva de la vacilación entre lo real y lo sobrenatural, como sucede en los relatos de corte fantástico, sino de las limitaciones propias del trabajo de rememoración y de las múltiples posibilidades de narrar un hecho. La voz narrativa incorpora como acontecimiento la distancia temporal y la incertidumbre sobre algunos hechos; valora un suceso a la distancia, consciente de que la narración desentraña nuevos aspectos de un hecho narrado o de una imagen evocada. En el fragmento citado es posible apreciar una lógica en la que las disyuntivas o las alternativas conviven, quizá porque al paso del tiempo persisten los efectos inciertos (pero no contradictorios o excluyentes) de un hecho. Es decir, la inclusión de la disyuntiva en la narración no subraya nada más la dificultad de aclarar un punto oscuro en el recuerdo, sino también las ventajas de considerar más de una posibilidad para interpretarlo y representarlo.

Juan Tomás Martínez Gutiérrez: "Murallas, de Gabriel Bernal Granados. Una lectura a la luz de la tradición mexicana de la nouvelle sobre la memoria y el autodescubrimiento" 
Esta estrategia funciona también en la descripción de situaciones, objetos o hechos. Cito algunos ejemplos considerando que en su conjunto ilustran un fenómeno que, tal vez por su dispersión, puede pasar inadvertido: "He dicho «rodábamos» porque César iba a mi rueda. O aceleraba, trazando una diagonal derecha [...] lo que realmente nos guiaba era una línea blanca, tendida sobre la superficie como una serpentina. $O$ una víbora que hipnotizaba a quien fijaba en ella la mirada" (11). El respaldo abatible de un Renault 12 Routier "simulaba un prado en las vacaciones de verano o una camilla para recostar la bicicleta a todo lo largo, como una novia o un cadáver" (14); durante el sismo, recuerda un edificio "como una torre que se derrumbaba a la distancia. O mejor dicho, como una persona que respondiera a los primeros incentivos de un mareo" (17); en un viaje describe un vehículo que asciende por los caminos precarios: "Parece un camioncito de juguete, subiendo a las cumbres de un Himalaya coronado de neblina. O un anciano -decrépito- que apenas puede con la longitud de la pendiente" (59). El nexo disyuntivo introduce una segunda imagen no contrapuesta a la primera, sino complementaria; por acumulación se descubre una proximidad a veces clara, otras, sorprendente entre dos elementos o figuras. Este recurso retórico se encuentra estrechamente relacionado con la estructura de la nouvelle: propone situaciones en apariencia inconexas, algunas de las cuales constituyen verdaderos enigmas y que, no obstante, leídas en su conjunto develan su sentido. Esta idea actúa en distintos planos de la obra: "Ciertas imágenes - y un cúmulo de sensaciones aparentemente inconexas - se van agolpando en mi memoria, siguiendo el hilo conductor equivalente a una trayectoria precisa" (13). Aquello que es aparentemente inconexo encuentra en la escritura y la memoria una trayectoria, un sentido, atendiendo a la idea de dirección que este último término posee; es uno de los diversos elementos que dotan de continuidad a la obra y la transmutan en una unidad coherente.

Imbricado con el problema de la conexión y la trayectoria, se encuentra la noción de fisura, elemento que cohesiona las distintas narraciones en el plano temático y estructural. Tras el accidente, que termina en una fractura de muñeca, el protagonista narra su visita al hospital, "Un cubo de paredes grises arruinado por la lluvia" (14), que visto desde el interior se transformaba en un laberinto y la doctora obesa que lo atiende, en un minotauro. Las paredes, muros, laberintos y minotauros se convierten, a partir de entonces, en motivos de gran importancia en la narración. La fractura ósea se describe, en otra secuencia marcada por un blanco textual, en términos de un acto inaugural:

Recuerdo la grosería del diagnóstico y la belleza romana de una palabra que me acompañaría de por vida: fisura - la grieta que desvela el carácter fragmentario de un espacio aparentemente homogéneo. Los huesos se pueden astillar sin llegar a romperse, como las relaciones humanas; un matiz, una sutileza retórica que repercutía directamente sobre la naturaleza del lenguaje. (14-15, cursivas en el original)

Como las relaciones humanas o como las historias al interior de una obra literaria, parece decir el narrador. El pasaje, asimismo, subraya la precariedad de un espacio y lo prosaico de una situación

Juan Tomás Martínez Gutiérrez: "Murallas, de Gabriel Bernal Granados. Una lectura a la luz de la tradición mexicana de la nouvelle sobre la memoria y el autodescubrimiento" 
que posee al mismo tiempo un valor iniciático: "Es verdad, la escena, por más que me esforzara, me remite ahora a la trastienda de una carnicería de la segunda guerra mundial [...]. Lo que hoy es un quirófano, mañana puede convertirse en un despacho de contabilidad o en un establo, como en las fábulas de Kafka" (15, cursivas mías). La memoria y la escritura tienen ese función de transformar y reconfigurar un recuerdo o instaurar una imagen que transmite una verdad. La secuencia termina con la salida triunfal del "héroe" del hospital, con la mano enyesada "como si se tratara de un niño envuelto y perfumado" (15), aludiendo nuevamente al nacimiento, y concluye: "Al salir del laberinto, y después de haber enfrentado al Minotauro en su versión posmoderna, ya era yo un guerrero converso, fortalecido a pesar de su cansancio" (15). Posteriormente, el "guerrero" es atendido por su madre quien le cura las heridas con miel, mientras le exige que abandone ese deporte propio de las clases sociales más bajas. Él reflexiona sobre el hecho de que un artefacto tan delicado como el casco de ciclista haya sido la diferencia entre la vida y la muerte, "saberlo — concluye - engrandecía mi propia leyenda frente a los ojosespejo de principiante nato que era yo en esa época" (16).

En el pasaje arriba revisado es posible apreciar un recurso característico de la voz narrativa: el distanciamiento. Se recurre a la figuración de perspectivas valorativas diversas sobre un mismo hecho, en este caso entre la posibilidad de elegir entre la mirada de la madre y la del protagonista en el pasado (que parecen asistir a dos situaciones completamente diferentes); el narrador incorpora ambas y, al mismo tiempo, "glosa" desde un presente de la escritura. El procedimiento no siempre es perceptible debido al tono que dota de cierta homogeneidad a la narración, pero justamente el ritmo peculiar de la obra se relaciona con esa manera de incorporar perspectivas dispares. A su vez, el distanciamiento se articula con el problema de la memoria, pero también con la posibilidad de unir elementos en apariencia inconexos: la nouvelle se desarrolla en la tensión entre segmentación e integración.

La siguiente secuencia del mismo capítulo "7:19" inicia con un epígrafe: "Como vuelve de pronto/ un viejo sueño - Alfonso D’Aquino, «Digitaria exilis»” (16), y narra la experiencia del protagonista durante el sismo de 1985, que acabó con buena parte del Distrito Federal. De esta manera, una segunda fractura se instala, decisiva, en su vida. La catástrofe modifica la trayectoria vital del personaje porque, tras el temblor, tiene que cambiar de escuela apenas terminado el ciclo escolar (se intuye que debido a los daños materiales o a la necesidad de restaurar el inmueble). Gracias al cambio, el protagonista conoce al profesor "D", quien le hablará por primera vez de filosofía y literatura; escucha, aunque sin entender, explicaciones sobre el logro estético de la obra de Juan Rulfo; conoce a sus primeros mejores amigos quienes lo introducen a otro tipo de música (Radio Futura y su versión de Annabel Lee, por ejemplo) y con quienes comparte una iniciación en las artes plásticas; asimismo, aparece su primer amor, los incipientes juegos eróticos, y refiere, casi como un relato secundario la historia de Juan, el peluquero de la familia. En estas historias, referidas en secuencias breves, a veces intercaladas, se narran casi tres años de la vida del protagonista. Se percibe una narración signada por el enigma,

Juan Tomás Martínez Gutiérrez: "Murallas, de Gabriel Bernal Granados. Una lectura a la luz de la tradición mexicana de la nouvelle sobre la memoria y el autodescubrimiento" 
y en ella se insertan comentarios eruditos sobre algún pasaje o personaje. El narrador se aclara a sí mismo aquello que rememora y transforma en escritura, de ahí surge el tono ensayístico de algunos fragmentos. Así, cuando habla de Pedro Páramo, dice: "Le pedí a mi madre que me comprara el libro y lo leí sin entender nada, buscando una historia que no encontré por ningún lado" (21). Solo a la distancia las piezas del rompecabezas comienzan a encajar dentro de su cabeza:

Los personajes de Rulfo encarnan — se vuelven carne o se vuelven tierra- gracias a la palabras que profieren, como si fueran fantasmas, exhalaciones de un tabaco que alguien fuma al mismo tiempo que está recordando. Y los personajes cuentan su historia [...]. El narrador apenas interviene, es un ser atormentado más, que mira la representación de una obra que él mismo está generando desde el patio de butacas. (22, cursiva en el original)

Es una reflexión sobre el arte de narrar, por supuesto, pero también un ejercicio que revela el carácter activo, creador y analítico de la memoria y la escritura, que aquí corren entreveradas, asimilándose mutuamente. El lector, por ejemplo, al colocar en perspectiva los episodios narrados, descubre que la historia de Juan, el peluquero, cumple diversas funciones: es la presencia de un ser tutelar, de alguien que instaura determinadas costumbres y rituales (menores, domésticos, quizás), pero también es un ser con un secreto que lo lleva a desaparecer un día sin decir nada. Lo único que el narrador puede hacer desde el presente es crear una hipótesis: es posible que haya huido por motivos políticos, quizá era un militante en la clandestinidad. Aparece entonces una fisura más: la del México de 1988, la elección presidencial fraudulenta de julio de ese año, y la persecución de disidentes. O tal vez era un hombre involucrado en negocios turbios. Juan encarna un enigma, está rodeado por el secreto y, paralelamente, dota de un trasfondo político a la época narrada. El primer capítulo, sabremos entonces, termina a la mitad del año señalado.

Hasta aquí es una serie de relatos que parecen engarzados sin un patrón determinado, excepto la secuencia temporal, pero justo se trata de la fisura que dota de coherencia al relato. Las líneas finales del capítulo "7:19" enlazan las secuencias narradas e invitan a seguir el vaivén de una voz que parece asediar la memoria más que verse asediado por ella; busca, rodea el secreto, como si la imposibilidad de penetrar más allá de lo posible constituyera la materialidad y la finalidad del relato:

Nada de lo que sucede en esta vida - o en la otra - es real. Todo es ajeno a las comprobaciones, y todo sin embargo se fija a las paredes de nuestros recuerdos con los alfileres instantáneos de nuestras intuiciones. O de la razón que se oculta detrás de cada primer golpe de vista. Ahí se encuentra la única verdad de las cosas. En los golpes que fijan como alfileres la vista sobre el muro inabarcable de la realidad en su conjunto. (31)

Posible arte poética de la nouvelle que el lector tiene en sus manos, la reflexión es también una forma de cohesionar la narración en el marco de un todo, la posibilidad de localizar puntos sobre la superficie de la experiencia o de la ficción.

Juan Tomás Martínez Gutiérrez: "Murallas, de Gabriel Bernal Granados. Una lectura a la luz de la tradición mexicana de la nouvelle sobre la memoria y el autodescubrimiento" 


\section{Sobre las ruinas, florecer}

En los siguientes capítulos se observa una relación, similar a la antes descrita, entre títulos y narración. Los primeros representan un enigma que, al menos parcialmente, se aclara con un elemento de la anécdota. Sin embargo, el esclarecimiento del enigma se dificulta debido a la dimensión alegórica que adquieren algunos componentes de la narración o, incluso, una secuencia misma. Un claro ejemplo se encuentra en el capítulo "Ventana al mar". Sin una ubicación ni un nexo temporal explícito, el pasaje, más que narrar, describe la relación del protagonista con su círculo de amigos. Esboza un mundo íntimo regido por la necesidad de definir y definirse respecto a los otros. El punto de unión entre este y el primer capítulo es el círculo de amigos. Si hacia el final del primer capítulo el narrador menciona los nombres de Lisandro y Rodrigo para referirse a sus compañeros (algunos años mayores y con quienes comparte gustos musicales), en este pasaje se delinean sus personalidades. Estudian pintura y sus primeros lienzos son en su mayoría imitaciones de Francis Bacon o Egon Schiele. La pintura, no obstante, rebasa la condición de referencia: junto al cine organiza el mundo, presta modelos que condensan un conflicto o un dilema. Así aparecen además Van Gogh para describir la pasión de Lisandro por las texturas y su incursión en drogas que intensifican la percepción del color, o Edward Hopper para describir la ambigüedad que adquieren las sombras en ciertos universos.

El título del capítulo se explica hacia el final, cuando se habla de un cuadro de Henri Matisse: "Como en muchos cuadros de Matisse de su época de exilio en Niza, durante la segunda guerra, la ventana que preside el interior del cuadro se abre de par en par hacia el muelle. Era la misma ventana de la casa de Matisse, en el número 1 de la calle Charles-Felix, que se metamorfoseaba de cuadro en cuadro y según los estados de ánimo del pintor" (42). Y luego, tras describir la composición del cuadro, agrega: "Pintura por lo tanto, «quieta», como la concentración de los estados de ánimo del artista, que se resuelven en sendas franjas de color blanco y gris. La lluvia, el invierno, la nostalgia. Y la imposibilidad de abrazar a los seres queridos. Solo, en compañía de su esposa y el mediterráneo como moderador, o testigo móvil en su eterno vaivén a la distancia, a través de la ventana" (43). De la ventana frente al mar, referencia a una serie de obras de Matisse, surge el título del capítulo. Mas, en un plano alegórico, la ventana frente al mar — un referente real que se metamorfosea en el arte permitiendo componer una escena completa - es al mismo tiempo una reflexión sobre la composición en la literatura y el emplazamiento de quien narra: se coloca a la distancia para componer una imagen, introduce un elemento repetitivo que manifiesta la tensión de los estados de ánimo de quien fabula. Asimismo, en la composición de Murallas, el capítulo cumple la función de dotar de una pausa a la narración: recompone el trazo, retoma la perspectiva y se prepara para seguir. Es otra de esas grietas que revelan el carácter en apariencia homogéneo de una narración. La ventana frente al mar sugiere la persistencia de elementos que pese a su aparente disparidad se conectan con una experiencia significativa: la fisura, la muralla.

Juan Tomás Martínez Gutiérrez: "Murallas, de Gabriel Bernal Granados. Una lectura a la luz de la tradición mexicana de la nouvelle sobre la memoria y el autodescubrimiento" 
El capítulo titulado "89" retoma la narración en el punto en que se quedó al final del primero. Tras el sismo, el protagonista ingresa en otra escuela; es el primer año de la instrucción preuniversitaria. Inicia con un epígrafe, tomado de La canción de amor y de muerte del alférez Christoph Rilke, de Rainer Maria Rilke: "No hay nada que se oponga a ellos: no hay ayer, no hay mañana; pues el tiempo se ha derrumbado. Y es sobre sus ruinas donde ellos florecen" (45). El paratexto anticipa el tema del amor y sus impedimentos, de las ruinas sobre las que nace. En este capítulo se consolida una forma de narrar articulada en torno a motivos que aparecen transmutados de diversas formas: los muros, las fisuras, el (re)inicio. Es característica de Murallas en cuanto propuesta particular pero, como he señalado, es además un rasgo genérico propio de la nouvelle. Judith Leibowitz lo denomina theme-complexe (tema-conjunto, podría ser una traducción aproximada de lo que también describe como cluster of themes), un recurso por medio del cual el mismo objeto de la narración mantiene su posición central (Leibowitz, 1976: 16). Revisemos brevemente las soluciones compositivas que propone la novela y sus implicaciones en la propuesta estética.

En su nueva escuela, los salones de bachillerato se encontraban en un espacio subterráneo, desde el que era posible ver una muralla de piedra basáltica "que parecía la orilla circular de un foso adonde hubiésemos sido confinados lo alumnos" (45), sobre todo porque resultaba un verdadero castigo estar ahí en los meses de inverno. ${ }^{6}$ En ese lugar conoce a Elena, su maestra de historia, una joven de origen español que había llegado al país esperando hacer una vida con su novio mexicano; ahora naufragaba a la espera de poder regresar a su país. El narrador se enamora de ella, quien, finalmente, decide corresponderle en un encuentro que culmina con el acto sexual. El capítulo se articula en torno a una tensión semántica entre la contención (los muros y otros elementos relacionados) y la irrupción, y de ahí se propone la idea de resurgir entre los escombros, y conecta, asimismo, con el suceso del terremoto que trastornó la vida de la ciudad y sus habitantes.

El lugar subterráneo donde inicia la narración corrobora lo dicho. Una red semántica va desvelando lo que podríamos denominar un sistema de fortificaciones: del sótano de la escuela a la coraza que Elena había construido para mantener una distancia de sus alumnos (su ropa, sus ademanes); le sigue una historia sobre la adolescencia de Elena, en un convento, con una monja, una religiosa que "[t]enía la mirada oscura y una piel clarísima, tan clara como la cal de las murallas de una ciudad antigua" (48, cursivas mías), y quien introduce a Elena en un incipiente erotismo. El narrador se enfrenta a esa historia de paredes y muros, y descubre que no podrá derribarlos. En efecto, no lo hace; Elena le abre las puertas cuando todo parece perdido. Otro

\footnotetext{
${ }^{6}$ Se trata de un tipo de edificaciones muy comunes en el sur de la Ciudad de México. Algunas construcciones, sobre todo los edificios grandes, utilizaron la piedra basáltica propia de la zona para construir los cimientos o para crear muros de contención. Esa forma de construir, que aprovecha la abundante piedra volcánica de la zona, ayudó a mitigar los efectos del sismo de 1985. Muchas de las construcciones de la época sobreviven. Por ejemplo, existe una Escuela Preparatoria de los hermanos maristas en la calle Benjamín Franklin, al sur del D. F., como se cuenta en la nouvelle.
}

Juan Tomás Martínez Gutiérrez: "Murallas, de Gabriel Bernal Granados. Una lectura a la luz de la tradición mexicana de la nouvelle sobre la memoria y el autodescubrimiento" 
epígrafe aparece entre secuencias, retomado de Edad de hombre, de Michel Leiris: “... héroe —es decir, Holofernes - pasa del caos milagroso de la infancia al orden feroz de la virilidad" (51). La entrega sexual es el rito de paso por excelencia, en este caso, el juego entre el rechazo y la invitación de Elena se encuentra precedido por las líneas de Leiris: Holofernes entrando al orden feroz de la virilidad y Elena, transmutada en una moderna Judith, deja el país a los pocos días, sin volver a ver al narrador. El acto sexual posee tal capacidad de definición que adquiere esa connotación violenta de la anécdota bíblica. No solo aparece de pronto convertido en hombre, sino que ahora, por primera vez en la historia, emerge otro rasgo de él: la inicial de su primer nombre, "G", pero referida en tercera persona, como si de alguien más se tratara, ${ }^{7}$ una especie de (re)surgimiento o comienzo de su ser. Por el acto y la iniciativa de Elena nos es revelado parte de un enigma. No es, sin embargo, la primera vez que el narrador pasa de la primera a la tercera persona, incluso lo hace al interior de un mismo capítulo. Se trata de otra forma que adopta la estrategia de distanciamiento.

\section{El muro y la fisura como espacios de confluencia}

"P", de forma similar a "Una ventana frente al mar", es un capítulo que parece romper una cierta línea de continuidad, pero no es así: ambos cumplen la función de crear una pausa y abreviar una serie de cambios. "89" termina cuando G decide salir de la ciudad y viajar a Paracho, Michoacán, para olvidar a Elena. Las iniciales, asimismo, implican y figuran un destinatario: ¿el narrador escribe "G" y "P" para que sea imposible establecer un nexo entre escritura y referente real? ¿O porque no es necesario develar el nexo, ya que quien lee conoce el significado? La pregunta sería entonces quién es el destinatario: un amigo cercano o él mismo tratando de adoptar una mirada analítica sobre su propio pasado (o es una falsa disyuntiva, como otras que aparecen en la obra). La nouvelle no aclara ese enigma, pero el fenómeno explica el tono intimista y la libertad con la que se desplaza la voz narrativa. De esta manera, Murallas incorpora una serie de recursos para sustentar y validar las oscilaciones de la narración, así como los cambios de focalización y de perspectiva. Es posible que de esa problemática derive que una parte de la crítica considere a Murallas una serie de relatos y no una unidad.

"P", señalaba líneas arriba, impone un cambio de ritmo e incluso un cambio en la estilización realista de la obra. El viaje a Paracho es otro rito de iniciación: un viaje en el que convive con un chico de su edad que, inexplicablemente, comparte su erudición sobre pintura. G asiste al avistamiento de una sirena, y finalmente mantiene una charla que evoca los oráculos y que es referida en un tono con reminiscencias de Las enseñanzas de Don Juan, de Carlos Castaneda (título que citan en otra parte del libro), todo, además, referido con colores, trazos y

\footnotetext{
${ }^{7}$ La inicial "G" bien podría ser un guiño biográfico o autoficcional. No obstante, parece una marca muy débil para proponer una lectura a partir de ese elemento. La necesidad de no revelar el nombre del narrador-protagonista, en todo caso, inclina la balanza hacia una lectura alejada de esa problemática.

Juan Tomás Martínez Gutiérrez: "Murallas, de Gabriel Bernal Granados. Una lectura a la luz de la tradición mexicana de la nouvelle sobre la memoria y el autodescubrimiento" 
figuras insólitas que evocan el carácter delirante u onírico de la pintura de Van Gogh o Henri Rousseau:

“¿Pero qué me dices de la escena con el sillón color cereza, que aparece en medio de la selva y que supuestamente corresponde a Pierre Loti?" "Absolutamente nada. Creo que se trata en todo caso de una alucinación civilizada, como todo lo que ocurre en los cuadros de Rousseau. El charme de su pintura se traduce precisamente a esa imaginación civilizada, que todo lo lleva de la ciudad al campo, para perderlo ahí, como una curiosidad de orden arqueológico y atrabiliario". (64, cursivas en el original)

La conversación es una vez más una reflexión sobre el arte de narrar: trasladar de un espacio a otro, colocar situaciones fuera de su contexto "originario" para apreciarlas de otra manera; una "imaginación civilizada" que lleva una imagen o una situación a otro punto para componer un cuadro y, al mismo tiempo, para perderla en un ejercicio, por supuesto, intelectual, pero también vital: deriva de la necesidad de crear en y mediante el arte formas de comprender el mundo y comprenderse dentro de un mundo. Si "P" fuera el capítulo final estaríamos ante una obra que termina en un mundo de ensoñación, desproporcionado (de tal manera predomina la alusión a Henri Rousseau), y el lector podría cuestionarse sobre el estatuto "real" de lo anteriormente narrado. Pero el siguiente capítulo, "Arena Coliseo", restituye el tono y la codificación realista, se regresa al tópico del sismo y al ambiente familiar de regreso en el D. F. De la ciudad al campo y del campo a la ciudad: pérdida y restitución, el resurgimiento sobre los escombros.

El capítulo final se titula "90" y se refiere al año en que se ubican las últimas acciones narradas. Se describe una escena en la que una monja lleva a los alumnos de la escuela a ver $E l$ nombre de la rosa (1986), de Jean Jacques Annaud. ¿Qué pretendía la religiosa?, se pregunta el narrador. La película, piensa desde el presente de la escritura, es también una obra sobre la fisura: la fisura entre el pueblo y la Iglesia. Asimismo, la película lleva a la ficción el tema del desprendimiento. Tal vez haya sido la intención de la religiosa: "La Madre Alma me enseñaba a desprenderme de mis propios recuerdos y a capitalizarlos bajo la forma de un relato escurridizo y parco" (84). Esta conclusión a la que llega el narrador resemantiza lo narrado porque ahora la voz explicita el hecho de que la escritura ha avanzado a tientas buscando algo que se le escapa. No solo se han narrado las fisuras surgidas de lo que es posible saber, sino aquellas creadas por sus propios desplazamientos, por lo que ahora sabe. Así concluye respecto a la película y respecto a su propia narración: "Con los años Adso [el novicio que acompaña a Guillermo de Baskerville], convertido ahora en el narrador de su propia historia, se pregunta por el nombre de la rosa, que nunca conoció. La única ventaja narrativa que yo tendría sobre él sería que con el paso de los años yo sí llegaría a descubrir el verdadero nombre de esa flor" (84, cursivas en el original).

Murallas termina con una fecha: "Ciudad de México, a 17 de mayo de 2014". Aquello que narra, en efecto son las múltiples fisuras: el yo de ahora y el de ayer que es casi otro, que a veces tiene que narrarse en tercera persona para volverse carne, para materializarse. El relato escurridizo y parco gana una ventaja narrativa, conoce gracias a la distancia y narra en torno al

Juan Tomás Martínez Gutiérrez: "Murallas, de Gabriel Bernal Granados. Una lectura a la luz de la tradición mexicana de la nouvelle sobre la memoria y el autodescubrimiento" 
secreto y el enigma. Cuando el narrador afirma: "Con el paso de los años yo sí llegaría a descubrir el verdadero nombre de esa flor" (84), sabemos que no se refiere a Elena. Retiene una información que si bien no modifica los hechos del pasado, sí su comprensión. Los enigmas, los secretos, son en sí mismos fisuras. Lo anterior es un problema de forma narrativa que requiere una solución compositiva y nos remite a la forma de la nouvelle:

el secreto funciona como un mecanismo de construcción de la trama porque permite unir sobre un punto ciego una red de pequeñas historias que se articulan, de una manera inexplicable, pero se articulan. De ahí esa sensación de ambigüedad, de indecisión, de las múltiples significaciones que tiene una historia porque inmediatamente nosotros empezamos a incorporar razones para hacer circular esa historia con un orden que, en realidad, en el relato mismo ni nos desvela ni nos descubre. (Piglia, 1994: 200-201)

La nouvelle, concluye Piglia, se va "anudando en una historia que, sin embargo, no se disgrega porque se anuda en un punto oscuro" (1994: 201). En Murallas, el arte y la memoria permiten apreciar en distintas perspectivas una trayectoria vital. Esa lucha con los recuerdos evoca no un proceso tortuoso, sino un constante deambular por laberintos, calles, edificios, recuerdos. Construcciones en las que los muros juegan un papel unas veces central, otras, secundario, pero cuya presencia parece afirmar la materialidad de la experiencia. Lo anterior explica el tono de la narración, por momentos nostálgico, pero también esa tendencia a narrar hechos mínimos como si fueran descubrimiento o iluminaciones. Las murallas a las que se refiere el título, por lo tanto, encuentran su correspondencia en el motivo de las superficies. Estas funcionan como divisiones para compartimentar una realidad y al mismo tiempo superficies sobre las que se puede colocar una imagen enmarcada. La voz narrativa, en resumen, propone una composición hecha de secuencias, cuyo valor reside en su capacidad de revelar una verdad y no en la correspondencia con un hecho verificable.

Murallas es una nouvelle con una propuesta estética sólida gracias a sus fisuras, valga el juego de palabras, porque se articula sobre una idea que la dota de sentido: los "puntos oscuros" de los que habla Piglia. Esta nouvelle capitaliza (para emplear una palabra del narrador) su dispersión, y crea un universo coherente en el que las variaciones en el tono y la contundencia de la frase, los desplazamientos y distanciamientos, exhiben una mirada retrospectiva sobre un mundo que parece perdido, una ciudad a finales del siglo $\mathrm{xx}$, la educación sentimental de una generación, vestigios de un mundo que parece destinado a desaparecer como la infancia misma.

\section{Bibliografía}

AGUILAR SOSA, Yanet: "Murallas explora las fisuras de la memoria”, El Universal, México, http://www.eluniversal.com.mx/articulo/cultura/letras/2015/08/5/murallas-explora-las-fisuras-dela-memoria, 17/04/2016.

BERNAL GRANADOS, Gabriel (2015): Murallas. México, CONACULTA.

Juan Tomás Martínez Gutiérrez: "Murallas, de Gabriel Bernal Granados. Una lectura a la luz de la tradición mexicana de la nouvelle sobre la memoria y el autodescubrimiento" 
ESTRADA, Sylvia Georgina: “Gabriel Bernal Granados muestra ficción de la memoria”, Zócalo, México, http://www.zocalo.com.mx/seccion/articulo/gabriel-bernal-granados-muestra-ficcion-dela-memoria-1446707001, 03/02/2016.

GONZÁLEZ RODRÍGUEZ, Sergio (2016): "Escribir libros como se escriben cartas a un amigo [reseña de Murallas, de Gabriel Granados]", Tierra Adentro, México, http://www.tierraadentro.cultura.gob.mx/critica-libros/escribir-libros-como-se-escriben-cartas-aun-amigo/, 01/05/2016.

LEIBOWITZ, Judith (1974): Narrative Purpose in the Novella. La Haya, Mouton.

PIGLIA, Ricardo (1994): "Secreto y narración. Tesis sobre la nouvelle". En Eduardo BECERRA (ed): El arquero inmóvil. Nuevas poéticas sobre el cuento.. Madrid, Páginas de Espuma, 187-205. SALMERÓN, Miguel (2002): La novela de formación y peripecia. Madrid, A. Machado Libros. SECRETARÍA DE CULTURA: "Presentó Conaculta dos obras recientes de la colección El Guardagujas: Ojos en la sombra y Murallas" [Comunicado No. 2437/2015], México, cultura.gob.mx, http://www.cultura.gob.mx/noticias/libros-revistas-y-literatura/43718-presentoconaculta-dos-obras-recientes-de-la-coleccion-el-guardagujas:-ojos-en-la-sombra-ymurallas.html, 03/02/2016.

C) Juan Tomás Martínez Gutiérrez

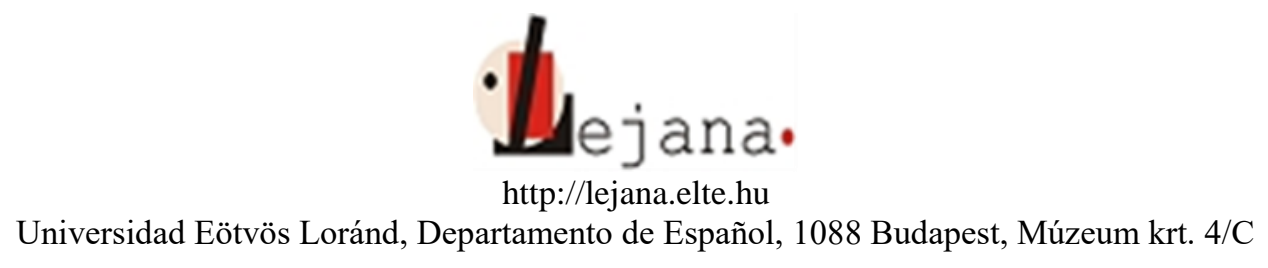

Recibido: 06 de junio de 2016

Aceptado: 07 de julio de 2016

Juan Tomás Martínez Gutiérrez: "Murallas, de Gabriel Bernal Granados. Una lectura a la luz de la tradición mexicana de la nouvelle sobre la memoria y el autodescubrimiento" 